\title{
LA IGLESIA Y EL PROCESO DE SECULARIZACIÓN EN EL URUGUAY MODERNO (1859-1919)**
}

\author{
POR \\ TOMÁS SANSÓN CORBO \\ Universidad de la República (Uruguay)
}

\begin{abstract}
RESUMEN
Uruguay se caracteriza, entre otras cosas, por ser un país eminentemente laicista. La Constitución de 1917 consagró la separación absoluta de la Iglesia y el Estado y puso fin a un largo proceso de secularización iniciado en 1859. La Iglesia perdió su preponderancia sociocultural y desde el Estado se articuló un imaginario colectivo prescindente de referentes religiosos. En este artículo pretendo analizar la frustrada lucha de la Iglesia por conservar su influencia sociocultural y las estrategias articuladas en varios frentes (pastoral, educativo, periodístico, político, catequético) para evitar lo que en la época se denominó la «descristianización». Este enfoque contribuye a explicar los rasgos originales de la Iglesia uruguaya y el carácter de sus relaciones con la sociedad y el Estado.
\end{abstract}

PALABRAS CLAVE: Iglesia, Uruguay, secularización, siglo XIX.

\section{THE CHURCH AND THE PROCESS OF SECULARIZATION IN THE MODERN URUGUAY (1859-1919)}

\begin{abstract}
Uruguay is characterized itself by, among other things, to be an eminent secular country. The Constitution of 1917 established the absolute separation of the Church and the State and it put an end to a long process of secularization initiated in 1859. The Church lost its socio-cultural preponderance, and from the
\end{abstract}

* ReFEREnCIAS: ACEM: Archivo de la Curia Eclesiástica de Montevideo; APNSM: Archivo de la Parroquia Nuestra Señora de las Mercedes; APNSR: Archivo de la Parroquia Nuestra Señora del Rosario; C: Cajón; c: Carpeta. 
State was articulated an imaginary collective devoid of any religious point of reference. In this article, I expect to analyze the unsuccessful fight of the Church to preserve its socio-cultural influence and the strategies structured in several fronts -pastoral, formative, journalistic, political, catechism educational- to avoid what in the time, was denominated the «Dechristianization». This approach leads to explain the original features of the Uruguayan Church and the character of its relationships with the society and the State.

KEY WORDS: Church, Uruguay, secularization, XIX century.

Recibido/Received 16-02-2010

Aceptad/Accepted 16-11-2010

\section{CONTEXTO HISTÓRICO}

El territorio que conforma la Provincia Eclesiástica del Uruguay perteneció, sucesivamente, a las diócesis de Lima (1543-1547), Asunción (1547-1582) y Buenos Aires (1582-1832).

Durante el período colonial la Iglesia estaba profundamente unida al Estado. El Rey recibió, paulatinamente, amplias potestades otorgadas por la Santa Sede para evangelizar el Nuevo Mundo. ${ }^{1}$ El conjunto de concesiones constituyeron el «Patronato Real», signo jurídico de la implantación de la cristiandad en Indias. Comprenderlo es fundamental para entender la historia eclesiástica latinoamericana y, en particular, la uruguaya.

Durante el período comprendido entre la erección del obispado de Buenos Aires (1620) y la fundación de Montevideo (1724) comenzó la acción evangelizadora en la Banda Oriental ${ }^{2}$ y las primeras modalidades de implantación eclesiástica.

La Banda Oriental fue denominada «tierra sin ningún provecho» por las autoridades españolas en el siglo XVI en función de la escasez de metales preciosos. La presencia de tribus indómitas retrasó notoriamente el poblamiento y desalentó la realización de esfuerzos misioneros intensos pues el estadio cultural de los nativos, recolectores y cazadores, los hacía poco proclives a la conversión. La evangelización fue tan tardía como la colonización.

\footnotetext{
${ }^{1}$ Las concesiones del Papa se dieron de forma paulatina y su conjunto constituye el corpus jurídico que rigió la relación entra la Corona y la Iglesia católica en Indias. Esta legislación es contemporánea del descubrimiento, tuvo comienzo con la bula Inter Caetera del papa Alejandro VI de mayo de 1493 y se fue configurando durante todo el período hispánico, tanto por decisiones pontificias, como por una jurisprudencia propia que se caracterizó por un marcado tinte regalista.

La disposición que de hecho otorgó al Rey de España y a sus descendientes el Patronato, es la bula Universalis Ecclesiae de Julio II del 28 de julio de 1507 (cfr. Cayetano BRUno, Historia de la Iglesia en la Argentina, Buenos Aires, 1966, t. I, 111).

${ }^{2}$ Denominación que recibió en la época colonial el territorio de la actual República Oriental del Uruguay.
}

Hispania Sacra, LXIII

127, enero-junio 2011, 283-303, ISSN: 0018-215-X 
No hubo condiciones favorables para una efectiva consolidación de la instituciones eclesiásticas. Es indudable que existió una cristiandad colonial, pero fue epidérmica, un leve barniz que coloreó las formas de la vida cotidiana en las ciudades, estimuló la mentalidad mágica y supersticiosa de los «hombres sueltos de la campaña", criollos y mestizos, y resultó indiferente para la gran mayoría de las parcialidades indígenas. Careció de la profundidad que adquirió en otras regiones de América como Colombia, México y Perú, en las que existieron tempranamente sedes arzobispales. En la Banda Oriental faltaron difusores eficaces y guardianes de las pautas religiosas que resultaron tan operativas para la Corona y la Iglesia.

Hubo una marcada heteronomía institucional, dependencia absoluta del obispado de Buenos Aires, que impidió mayor dinamismo en la resolución de problemas. Faltaron iniciativas y/o recursos para establecer monasterios, escuelas y universidades que hubieran dado a la sociedad colonial una dimensión sociocultural más elevada. La acción eclesiástica quedó librada a la iniciativa y posibilidades de unos pocos clérigos que hacían lo que las circunstancias personales y colectivas les permitían. Faltó la presencia permanente y cercana del obispo que actuara como fiscalizador, animador de las comunidades parroquiales y conventuales y de los servicios religiosos y sociales prestados por las mismas.

Con la fundación de núcleos poblados, fundamentalmente Montevideo, comenzó una modesta acción evangelizadora. ${ }^{3}$

Durante el proceso revolucionario (1811-1830) la mayoría del clero oriental se manifestó a favor de la Independencia. Los franciscanos, por ejemplo, fueron expulsados en 1811 del Montevideo dominado por los españoles a causa de su abierta simpatía con los revolucionarios. En 1812 murió el último obispo español de Buenos Aires, Mons. Benito Lué y Riega. En función del Patronato y de la situación de guerra con España fue imposible designar un nuevo prelado; la Sede fue administrada por sucesivos Provisores. En 1815 José Artigas, caudillo revolucionario. logró que las autoridades eclesiásticas bonaerenses reconocieran amplios poderes al titular de la Matriz de Montevideo, Padre Dámaso Antonio Larrañaga, sobre todo el territorio de la Provincia Oriental. En 1824 la Santa Sede intentó desbloquear la inercia, en que habían caído sus relaciones con las iglesias particulares latinoamericanas, y envió a Mons. Juan Muzi como Nuncio a América Latina. Al pasar por Uruguay ratificó a Larrañaga como Vicario.

Uruguay comenzó efectivamente su vida independiente el 18 de julio 1830 cuando se juró la Constitución. Su artículo 5 establecía: «La Religión del Esta-

${ }^{3}$ El establecimiento de reducciones indígenas administradas por franciscanos fue muy limitado, solamente una, la de Santo Domingo Soriano, tuvo relativo éxito. El carácter indómito de los nativos de esta región resultó fundamental para explicar estos fracasos. 
do es la Católica Apostólica Romana». La fórmula surgió luego de muchos debates entre los constituyentes.

Jerárquicamente la Iglesia uruguaya seguía dependiendo de la antigua Sede Episcopal de Buenos Aires. El 2 de agosto de 1832 el Papa Gregorio XVI creó el Vicariato Apostólico del Uruguay y designó titular del mismo al Pbro. Larrañaga, quien ocupó el cargo hasta su muerte en 1848. Los vicarios posteriores fueron: Lorenzo Fernández (1848-1852), Benito Lamas (1854-1857), Juan Domingo Fernández (1857-1859), y Jacinto Vera (1859-1878). El 16 de julio de 1865 el Papa Pío IX consagró a Vera obispo titular de Megara «in partibus infidelium». En 1878 se convirtió en el primer obispo uruguayo al crearse la Diócesis de Montevideo.

En el período entre la independencia y la erección del obispado, la Iglesia evidenció una notoria debilidad estructural, consecuencia de la evangelización tardía y la inexistencia de un centro eclesiástico importante. El Derecho de Patronato heredado por el Estado provocó frecuentes roces; la Iglesia debió confrontar en el plano ideológico contra masones y racionalistas; tenía un escaso número de sacerdotes para cubrir las necesidades espirituales de los fieles.

Durante la Guerra Grande (1839-1852) la Iglesia quedó dividida. En el denominado «Gobierno del Cerrito», Larrañaga mantuvo su autoridad, pero en la ciudad de Montevideo sitiada, «Gobierno de la Defensa», el Presbítero Lorenzo Fernández gobernó como Provisor Eclesiástico.

En 1842 los jesuitas retornaron al país por primera vez luego de su expulsión en el siglo XVIII. Su fidelidad a Roma y su férrea defensa de la autoridad pontificia desentonó y chocó abiertamente con los intereses del Gobierno por mantener sujeta y sumisa a la Iglesia y a sus pastores.

En 1856 el Vicario Lamas publicó un documento recordado la condena contra la masonería. Estas y la Iglesia se enfrentaron duramente y comenzaron a distanciarse progresivamente. El 26 de enero de 1859, el Presidente de la República decretó la expulsión de los jesuitas por manifestaciones antimasónicas de algunos de sus miembros. Pero el conflicto más sonado fue a raíz de la muerte, 15 de abril de 1861 y en la ciudad de San José, del médico Enrique Jacobson, católico y masón: las autoridades eclesiásticas se negaron a sepultar sus restos en el cementerio. Eso provocó un enfrentamiento que culminó con la secularización de las necrópolis por parte del Estado.

Hubo serias polémicas internas en la Iglesia que generaron la decisión de Vera de sustituir al párroco de la catedral de Montevideo, Padre Juan Brid, sacerdote de tendencia masónica, por Inocencio María Yéregui. El Presidente Bernardo Berro no lo aceptó. En virtud del Patronato, anuló el pase dado el año anterior al Breve Pontificio que designaba Vicario a Vera, quien fue desterrado el 7 de octubre de 1862 y se refugió en Buenos Aires. En agosto de 1863 se rec- 
tificó y consiguió convencer a Vera de retornar a Uruguay. Tal actitud fue condicionada por la coyuntura política del momento: el Presidente no quería que el problema eclesiástico fuera una causa más de respaldo al caudillo Venancio Flores, quien estaba preparando una revolución. Estos acontecimientos marcaron el comienzo del proceso de secularización.

En la década de 1860 se inició una etapa de profundas transformaciones estructurales en Uruguay que duró cuatro décadas y se conoce como «modernización». Este concepto ha sido utilizado «para dar cuenta del proceso de tránsito de una sociedad de la 'tradicionalidad' a la 'modernidad'. Ese proceso combina-aunque no siempre todos, ni todos contemporáneamente- los siguientes factores: urbanización, industrialización, superación de pautas tradicionales de comportamiento, eliminación de referentes religiosos de la normativa social, y articulación de una estructura política democrática y participativa». 4 Carlos Zubillaga y Mario Cayota distinguen dos modelos preponderantes en el proceso modernizador: el agro-exportador ${ }^{5}$ y el urbano-industrial. ${ }^{6}$

En la época de la modernización el Estado uruguayo debió «imaginar» una nación. Intelectuales como Francisco Bauzá, Juan Zorrilla de San Martín, Juan Manuel Blanes y José Pedro Varela, entre otros, contribuyeron a construir un pasado, crear una identidad colectiva, con un fuerte carácter laico, y a afirmar la viabilidad del país.

Las corrientes de pensamiento imperante en el período fueron el espiritualismo y el positivismo. ${ }^{7}$

El espiritualismo ${ }^{8}$ de origen francés fue introducido en Uruguay en 1848 por el Prof. José de la Peña, catedrático de Filosofía de la Universidad. Esta escue-

\footnotetext{
${ }^{4}$ C. Zubillaga y M. Cayota, Cristianos y cambio social, Montevideo, 1982, t. I, 97.

${ }^{5}$ Llevado adelante por lo que José Pedro Barrán y Benjamín Nahum denominaron «la nueva clase alta rural» (J. P. BARRAN, B. NAHUM, Historia rural del Uruguay Moderno, Montevideo, 1967, t. I,). Estaba integrada por «estancieros que concebían la explotación ganadera como una 'empresa', fue el sustractum desde el que partió la acción de la Asociación Rural, impulsora de la modernización». Este sector presentaba una «visión unilateral del modelo de desarrollo» privilegiando una racional explotación agropecuaria y asegurando el orden en la campaña gracias al concurso del Estado militarista. El modelo feneció aproximadamente en 1886 por falta de inversión de capitales y por «las divergencias subsiguientes entre los productores agropecuarios, que enfrentaban al sector modernizador nucleado en la Asociación Rural con el sector de los estancieros tasajeros» (C. ZuBILLAGA - M. CAYOTA, 101).

${ }^{6} \mathrm{El}$ modelo urbano-industrial comenzó a fines de la década de 1880. Fue impulsado por las políticas civilistas y la todavía débil burguesía industrial. Puso en práctica una política proteccionista que permitió obrar con cierta independencia de los intereses extranjeros.

${ }^{7} \mathrm{~A}$. ARDAO es el autor uruguayo que mejor ha estudiado este fenómeno en dos obras clásicas: Espiritualismo y positivismo en el Uruguay, Montevideo, 1968 y Racionalismo y liberalismo en el Uruguay, Montevideo, 1963.

${ }^{8}$ El espiritualismo ecléctico nació en Francia a comienzos del siglo XIX y tuvo como principal exponente a Víctor Cousin. Se trata de un movimiento que procuró realizar una síntesis de los elementos más positivos de distintas escuelas de pensamiento. Tuvo su apogeo durante el reinado de Luis Felipe
} 
la, hegemónica durante 25 años, formó ideológicamente a la clase dirigente en un teoricismo acendrado -el fracaso del Principismo, expresión política de esta filosofía, revela las carencias de estos hombres para enfrentar los problemas del país. Creó las condiciones para el desarrollo del racionalismo religioso. La «Profesión de Fe Racionalista» de 1872 estaba impregnada de una ética y un deísmo característicos del espiritualismo.

En la segunda mitad de la década de 1870 ingresó al país el positivismo. ${ }^{9}$ A partir de 1880 cambió la orientación filosófica de la Universidad. Su rápido éxito estuvo vinculado a la instalación de las primeras cátedras de la Facultad de Medicina (1876) y al estudio de las ciencias naturales que permitieron la consolidación de lo que Arturo Ardao denominó «la cultura científica» del siglo. ${ }^{10}$ El positivismo influyó en distintos planos, contribuyó a crear en los gobernantes una mentalidad nueva para enfrentar y solucionar los problemas nacionales. Las medidas comenzaron a tomarse en base a necesidades y hechos concretos, incorporándose el concepto de evolución a todas las realidades sociales y culturales. A nivel educativo, la reforma vareliana recogió elementos positivistas que se reflejaron en la tendencia científica y naturalista de la misma.

En materia religiosa tanto el espiritualismo como el positivismo eran racionalistas. ${ }^{11}$ En Uruguay el racionalismo decimonónico evolucionó rápidamente en distintas etapas y bajo su hegemonía intelectual se concretó el proceso de secularización. Cada etapa estuvo marcada por un conflicto religioso:

1. racionalismo teísta (1850-1865, enfrentamiento entre masones católicos y jesuitas);

2. racionalismo deísta (1865-1880, racionalistas propiamente dichos contra católicos en general); y

3. racionalismo ateo o agnóstico (1880-1925, liberales frente a clericales) ${ }^{12}$.

de Orleans y llegó a dominar las cátedras universitarias. Posteriormente comenzó a decaer frente a los avances del positivismo. Uno de sus textos clásicos, muy utilizado con fines didácticos, fue el Cours de philosophie de Eugenio Geruzez.

${ }^{9}$ A propósito del mismo nos dice Arturo Ardao: «Atendido lo esencial, la filosofía positivista surgió en el siglo XIX como un gran movimiento de reacción contra la metafísica, llevado a cabo en nombre de la ciencia, y en particular de la ciencia de la naturaleza. (...) Ante todo representó el positivismo la síntesis del racionalismo con el empirismo. (...) El positivismo como escuela fue fundado en Francia por Augusto Comte (...)» (A. ARDAO, Espiritualismo... 67-70).

${ }^{10}$ Cfr. ibidem, 61 y 108.

${ }^{11}$ Ardao define al racionalismo religioso, como «toda posición que proclame o reivindique los derechos de la razón frente al dogmatismo teológico de la fe, aunque no siempre llegue a romper con ese dogmatismo» (A. ARDAO, Racionalismo... 11).

${ }^{12}$ Las fechas indicadas deben tomarse como límites aproximados y no implican la desaparición de las formas anteriores.

Hispania Sacra, LXIII

127, enero-junio 2011, 283-303, ISSN: 0018-215-X 
El modelo de cristiandad fue confrontado y puesto en cuestión por las medidas anticlericales, que jalonaron la secularización de un Estado fuertemente influido por el racionalismo y el positivismo. Las autoridades eclesiásticas no escaparon a este movimiento que envolvió a toda la sociedad uruguaya y necesariamente tuvieron que «imaginar» una Iglesia adaptada a la nueva y desafiante realidad.

El 16 de julio de 1865 el Papa Pío IX consagró al Vicario Apostólico, Pbro. Jacinto Vera, ${ }^{13}$ obispo titular de Megara «in partibus infidelium». Esta disposición coadyuvó a jerarquizar la institución y dotar a su máxima autoridad de la dignidad y poderes jurisdiccionales para enfrentar los embates anticlericales. El proceso de consolidación institucional tuvo un hito fundamental en 1878 cuando el Vicariato fue elevado a la categoría de Diócesis. Vera se transformó en el primer obispo de Montevideo con autoridad sobre todo el territorio nacional. Desempeñó un rol trascendente en la organización de la iglesia uruguaya hasta su muerte en 1881.

Vera y sus sucesores Inocencio María Yéregui, obispo entre 1881 y 1891, y Mariano Soler, ${ }^{14}$ obispo a partir de 1891 y Arzobispo desde 1897 hasta su muerte en 1908, debieron enfrentar críticas situaciones: ad extra, los embates del anticlericalismo y ad intra problemas económicos y organizativos.

La pobreza edilicia y ornamental de los templos de campaña era notoria y provocaba reclamos por parte de los fieles que querían dignificar sus lugares de culto. Algunas capillas de parajes muy apartados carecían de los elementos necesarios para la realización de ceremonias religiosas. En ocasiones los sacerdotes no podían bautizar por la falta de crismeras. Los útiles litúrgicos eran muy escasos. ${ }^{15}$

\footnotetext{
${ }^{13}$ Gran organizador institucional de la Iglesia uruguaya que debió enfrentar serias dificultades desde el comienzo de su gestión. En la década de 1870 desarrolló una acción muy intensa: estimuló el ingreso al país de congregaciones religiosas como bayoneses, salesianos, capuchinos, vicentinas y jesuitas, entre otros; promovió a un grupo de clérigos y laicos jóvenes; contó incondicionalmente con el respaldo de los jesuitas. La Compañía de Jesús merece una mención especial pues constituyó en la primera época racionalista la avanzada de lucha contra la masonería católica. En los panfletos y en la prensa anticlerical posterior a la década de 1850 el término «jesuitismo» fue utilizado con una connotación peyorativa.

${ }^{14}$ Soler estudió entre 1863 y 1868 en el colegio Inmaculada Concepción de Santa Fe (Argentina) a cargo de los jesuitas, en 1869 viajó a Roma para completar sus estudios en el Colegio Pío Latinoamericano; entre 1871 y 1874 obtuvo los grados académicos de Licenciado y Doctor en Teología y en Derecho Canónico; en 1874 volvió a Montevideo y comenzó una intensa actividad, ocupó cargos importantes a nivel de Curia e incluso fue electo Diputado (1879-1882). Tuvo un rol preponderante en la segunda etapa de organización de la Iglesia. Durante su episcopado procuró aumentar el clero y mejorar la formación de los seminaristas. Gran polemista, luchó duramente contra el anticlericalismo acérrimo de la época. Viajó incansablemente, recorrió el mundo llegando en varias ocasiones a Tierra Santa. Falleció en 1908 cuando retornaba a Uruguay de uno de esos viajes.

${ }^{15}$ Algunos testimonios de época son elocuentes del estado material en que se encontraban las iglesias de campaña:
} 
Además de los problemas económicos, había otro muy importante y que persistió a largo plazo: la escasez de vocaciones sacerdotales. La situación era muy difícil en el interior de la República y estaba agravada por la enorme extensión de las circunscripciones parroquiales. La tarea evangelizadora estaba muy resentida y existieron abusos. Mons. Yéregui constataba dolorosamente este problema:

«Las parroquias no se hallan en estado más próspero porque, diré con sentimiento y sin pretender agraviar, que habiendo sido estas regenteadas por sacerdotes extranjeros, estos generalmente, y salvo honrosas excepciones, han procurado atesorar para retirarse a su país y no se han dedicado a las mejoras materiales o fundación de obras pías en las parroquias a su cargo». ${ }^{16}$

Las apreciaciones del prelado no eran exageradas. La poca dedicación de los sacerdotes a sus tareas pastorales era un mal de larga data en el país. En 1834 el cónsul de Francia en Uruguay describía con tintes sombríos el personal sacerdotal de la campaña y el descreimiento generalizado que había detectado:

«La religión, el freno más seguro para un pueblo ignorante y corrompido, es aquí completamente impotente para detener ese desborde de las costumbres y atemperar ese carácter de ferocidad. En campaña, las prácticas que prescribe son difíciles de observar, a causa de la gran distancia que separa las viviendas de los pueblos en que de ordinario se encuentran la iglesia y el domicilio de los curas. Así pasan los meses y los años sin que los pobladores asistan al servicio divino o a una instrucción pastoral. (...) la incredulidad se ha hecho una moda; y tales sentimientos se han transmitido así, de generación en generación hasta el presente. (...) Puede decirse que en este pueblo se han extinguido todos los sentimientos religiosos, o al menos que exagera su indiferencia en materia de Religión.

«Sr. Presbítero Nicolás Luquese: Desde el momento en que me hice cargo de esta Vice Parroquia por medio de VD. manifesté a Su Ilma. (...) las necesidades de ella, y entre las más urgentes (...) un misal: Vd. de respuesta me dijo: que no convenía comprar misal, porque se estaba reformando; y esto hace más de un año. Por la presente someto a la consideración de VD. que el misal existente en esta Iglesia es del año 1761, no contiene ninguna de las misas de los misterios de la Pasión de Jesucristo, nada le digo de las otras misas que contienen los otros misales que se imprimieron después de la indicada fecha (...). Si Su Sra. Ilma. creerá conveniente hacerme conseguir alguno de los muchos existentes en la catedral se lo agradecería, y con el tiempo comprar alguno después de la reforma» (Carta del Padre Vicente Caggiano al Padre Nicolás Luquese, s/d, ACEM. Obispado de Montevideo. Monseñor Inocencio Yéregui, C. 298, c. 3c).

Estos problemas no eran patrimonio del interior, Mons. Yéregui informaba que la propia Iglesia Catedral de Montevideo no tenía «rentas propias provenientes de beneficios, fundaciones o legados píos, sino las rentas de pie de altar que recibe por ser parroquia y que apenas son suficientes para atender al servicio que ha tenido siempre como iglesia Matriz de la Capital» (Cfr. I. Ma. YeREGUI, Visita Ad Limina. Estado de la diócesis de Montevideo (1888). ACEM. Obispado de Montevideo, Mons. Inocencio Ma. Yéregui, C. 298, c. 3b).

16 Idem.

Hispania Sacra, LXIII

127, enero-junio 2011, 283-303, ISSN: 0018-215-X 
«La ignorancia y la inconducta del clero han influido (...) en este abandono casi general de todos los principios religiosos. Pocos de nuestros pastores de aldea no serán infinitamente más instruidos que la mayor parte de los sacerdotes de esta capital. $Y$ en Francia no hay un solo ministro del Altar que dé el escándalo de un concubinato flagrante, como la mayor parte de los de esta república. El respeto por el culto se resiste por este estado de cosas, que ejerce una influencia funesta sobre la moral pública de todo el país». ${ }^{17}$

En 1904 había 139 sacerdotes para la atención pastoral de 51 parroquias, 9 viceparroquias y 42 capillas extendidas por todo el territorio nacional; 47 uruguayos y 92 extranjeros, 55 de los cuales no estaban incardinados..$^{18}$ El personal eclesiástico de los departamentos más alejados de la Capital era escaso, v.gr., dos sacerdotes en Artigas, uno en Salto y uno en Rivera. Primaba la heterogeneidad en cuanto niveles de instrucción y vivencia del compromiso ministerial. Monseñor Vera y sus sucesores hicieron denodados esfuerzos por crear un clero nacional con una formación intelectual sólida.

En 1897 el Papa León XIII creó la Provincia Eclesiástica del Uruguay conformada por el Arzobispado de Montevideo y las diócesis sufragáneas de Melo y Salto. Los desacuerdos con el gobierno determinaron que las nuevas diócesis permanecieran vacantes. Cuando en 1908 murió Mons. Mariano Soler quedó también acéfala la Sede Metropolitana. Mons. Ricardo Isasa asumió el gobierno de la Iglesia uruguaya en calidad de Administrador Apostólico. Le tocó enfrentar los últimos embates del secularismo anticlerical de José Batlle y Ordóñez, que derivó en la separación absoluta de la Iglesia y el Estado establecida en la Constitución de 1917.

Mons. Isasa fue sustituido en 1918 por el sacerdote redentorista José Johannemann, como designado por el Vaticano Visitador Apostólico y encargado de normalizar la situación de la proyectada Provincia Eclesiástica del Uruguay. Desarrolló su labor entre 1918 y 1919. En 1919, desaparecido el obstáculo del Patronato, fueron provistas las sedes vacantes: el Papa Benedicto XV designó a Juan Francisco Aragone Arzobispo de Montevideo; Tomás Camacho, Obispo de Salto; José Semería, Obispo de Melo. Se abría una nueva etapa en la historia de la Iglesia uruguaya...

17 «Informe del Señor Cónsul de Francia en Montevideo, M.R., Baredère, al Ministerio de relaciones Exteriores de Francia (1834)» Revista Histórica XXVIII (1958) 501-503.

${ }^{18}$ Datos tomados de ACEM, Censo, C. 173. 


\section{LA SECULARIZACIÓN Y SUS CONSECUENCIAS}

La secularización ${ }^{19}$ fue un lento pero sostenido proceso de diferenciación de campos de influencia, ${ }^{20}$ jalonado por una serie de enfrentamientos entre la Iglesia y el Estado. Se desarrolló durante las últimas cuatro décadas del siglo XIX y comienzos del XX, coincidiendo con la modernización del país.

Los antecedentes del conflicto se encuentran a finales de la década de 1850, durante el vicariato de Lamas. Éste hizo pública una carta pastoral referida a los problemas de la Iglesia y advertía a los clérigos sobre la amenaza de la masonería y el racionalismo:

«Rodeados de una vana y engañosa filosofía, y poco observada en algunos puntos la disciplina eclesiástica, nos desentenderíamos de un deber gravísimo y seríamos unos mercenarios infieles, si no os dirigiésemos nuestras letras. (...)

«Venerables sacerdotes: vosotros sois el primer objeto de nuestra solicitud. Por vuestro elevado estado sois el espejo en que se miran los demás. De vuestro arreglo pende ciertamente el de todo el pueblo. Vosotros sois los ministros del Señor, y como tales, os corresponde promover la observancia de la divina Ley, no menos con las obras que con las palabras. A vosotros toca celar el decoro de su sagrado Templo, la pureza de la religión, la reforma de las costumbres, ofreciendo con vuestros procedimientos el mejor modelo».21

En 1856 publicó otro documento recordando la condena eclesial sobre la masonería.

El 26 de enero de 1859, el Presidente de la República decretó la expulsión de los jesuitas por manifestaciones antimasónicas de algunos de sus miembros. En 1861 se produjeron los acontecimientos relatados en el apartado anterior, vinculados con la muerte de Jacobson y que derivaron en la municipalización de los cementerios. A partir de entonces la relación entre Iglesia y Estado se

${ }^{19}$ Categoría polisémica y controvertida que ha dado lugar a muchos debates y reformulaciones teóricas (F. Ferrarotti et al., Sociologia da religiao, San Pablo, 1990; R. Diaz-SalazAR - S. Giner F. VelasCo, Formas modernas de religión, Madrid, 1994). En este artículo es entendido y manejado operativamente como proceso de enfrentamiento, separación y autonomización de las esferas de acción e influencia de la Iglesia y el Estado. El resultado del mismo, en la sociedad uruguaya, fue una importante privatización de lo religioso, fenómeno que diferencia y caracteriza al país en el contexto latinoamericano (cfr.: R. Blancarte, «Laicidad y secularización en México», Estudios Sociológicos, El Colegio de México XIX (2001) 843-855).

${ }^{20}$ Cfr.: C. Zubillaga y M. CAYOta, Cristianos y cambio social...; J. P. BARRAn, Iglesia Católica y burguesía en el Uruguay de la modernización (1860-1900), Montevideo, 1988; G. CAETANO y R. GEYMONAT, La secularización uruguaya (1859-1919). Catolicismo y privatización de lo religioso, Montevideo, 1997; D. Sturla, ¿Santa o de Turismo? Calendario y secularización en el Uruguay, Montevideo, 2010.

${ }^{21}$ Pastoral del Ilustrísimo y Reverendísimo Sr. Vicario Apostólico de esta República. D. José Benito Lamas. A su respetable clero y a todos los fieles, 28 de setiembre de 1854.

Hispania Sacra, LXIII

127, enero-junio 2011, 283-303, ISSN: 0018-215-X 
hizo cada vez más tensa. Se crearon una serie de normas lesivas para la Iglesia, pero hubo dos particularmente importantes: las leyes de Registro de Estado Civil (1879) y de Matrimonio Civil Obligatorio (1885). Ambas erosionaron y debilitaron la influencia eclesiástica pues le quitaron el monopolio de la inscripción de bautismos, matrimonios y defunciones.

La ley de 1879 generó muchos problemas. Algunos jueces y fiscales la interpretaban en el sentido de que prohibía a los sacerdotes realizar el bautismo sin la constancia de la anotación en el Registro Civil. ${ }^{22}$ Resulta ilustrativo el caso del Párroco de Durazno, Juan Cruz Echenique quien en una carta dirigida al Vicario General y Gobernador de la Arquidiócesis explica la situación que le tocó vivir:

«Accediendo por fin a las reiteradas indicaciones de V.E. hoy he hecho presentar la fianza para mi excarcelación. (...)

"Como V.E. puede enterarse del expediente, aquí ya no se trata de si los curas pueden o no inscribir en los libros parroquiales las partidas de las criaturas que se bautizan sin el certificado de su inscripción en el Registro Civil, que es a lo único que se refiere el Artículo 37 de la Ley de Registro Civil. Aquí se trata directamente de si se pueden o no bautizar esas criaturas sin el peligro de ir a una cárcel a la simple denuncia de un mentecato sin sentido común y de un fiscal sectario y hambriento de la persecución clerical, como dicen ser (como lo prueban con los hechos) el del Durazno, con el concurso de un juez letrado que, ofuscado también por el espíritu liberal, cree que el Art. 37 (...) no solo prohíbe la inscripción en los libros de las criaturas que no traen certificado, sino también el mismo Bautismo: pues no se comprende de otra manera el auto de prisión en las circunstancias en que se ha dictado. (...)

"¿Se creerán estos nuevos Nerones que, puesto el Clero Diocesano con sus autoridades a la cabeza en la alternativa de obedecer a Dios o a los hombres dudarán en la elección? (...) ¡Insensatos!»23

Las cifras de bautismos y matrimonios ofrecen importantes datos para «medir» la «descristianización» de la sociedad tal como la percibían los actores eclesiásticos. Ofrecemos a continuación una serie de cuadros estadísticos que permiten comparar el número de matrimonios religiosos y bautismos celebrados antes y después de 1885 en algunas parroquias de Montevideo e interior, y datos particulares de la Parroquia de San Eugenio, Departamento de Artigas, donde se informa sobre la situación filiatoria de los bautizados.

${ }^{22} \mathrm{El}$ artículo 37 de la ley de 1879 establecía claramente que «(...) los curas párrocos no admitirán inscripción alguna de bautismo en sus libros parroquiales, sin que los interesados exhiban previamente el correspondiente certificado de inscripción en el Registro Civil de nacimiento» (Ma. GRIEGO y otros, Monseñor Soler. Acción y obras, Montevideo, 1991, 120).

Siendo diputado, Soler propuso el 25 de junio de 1880 en la Cámara la supresión de este artículo por considerarlo inconveniente. No tuvo éxito, la votación le fue adversa y el artículo siguió vigente.

${ }^{23}$ Carta de Juan Cruz Echenique a Santiago Haretche, 16 de agosto de 1899. APNSM. C. Asuntos Generales (1827-1909), c. Asuntos Varios, 1889-1909. 
Los datos del cuadro I evidencian que en la gran mayoría de las parroquias descendió notoriamente el número de matrimonios. Hubo una disminución del $38 \%$ que en algunos casos llegó al 82\% (Tacuarembó). Las cifras tienden a aumentar en los departamentos más alejados de Montevideo con menor presencia clerical. Largas distancias, escasez de sacerdotes, costo de los derechos eclesiásticos, y la posibilidad de legalizar civilmente las uniones de hecho, fueron los factores esenciales que oficiaron como inhibidores en muchas parejas para contraer matrimonio religioso.

\section{Cuadro I \\ Matrimonios}

\begin{tabular}{|l|r|r|r|c|}
\hline Parroquias & $\mathbf{1 8 7 0 - 8 5}$ & Promedio & $\mathbf{1 8 9 6 - 9 0 0}$ & Promedio \\
\hline Matriz & 6.000 & 375 & 3.545 & 236 \\
\hline Unión & 1.066 & 66 & 1.219 & 81 \\
\hline Canelones & 1.746 & 109 & 975 & 65 \\
\hline Tala & 1.141 & 71 & 826 & 55 \\
\hline Florida & 1.317 & 82 & 943 & 62 \\
\hline Maldonado & 435 & 27 & 295 & 19 \\
\hline Melo & 1.487 & 92 & 443 & 29 \\
\hline Río Branco & 600 & 37 & 125 & 8 \\
\hline Rocha & 1.426 & 89 & 958 & 63 \\
\hline Paysandú & 2.027 & 126 & 1.322 & 88 \\
\hline Rivera & 331 & 22 & 182 & 12 \\
\hline Tacuarembó & 1.678 & 104 & 300 & 20 \\
\hline Salto & 2.029 & 126 & 761 & 50 \\
\hline Colonia & 506 & 31 & 481 & 32 \\
\hline San Eugenio (Artigas) & 1.025 & 64 & 307 & 20 \\
\hline Totales & 24.008 & 1.435 & 14.529 & 963 \\
\hline
\end{tabular}

Fuente: Estadísticas de matrimonios religiosos (1870-1900). ACEM, C. 173, c. Estadística. Nacimientos. Bautismos. Defunciones.

Las cifras de bautizados, que figuran en el cuadro II, no disminuyeron tanto como las de matrimonios y, en algunos casos, aumentaron. Para explicar esta diferencia estadística debemos tener en cuenta la significación del este sacramento: el bautismo estaba rodeado de un halo de sacralidad por su carácter de rito de iniciación y sacramento salvífico; era considerado impostergable mientras que el matrimonio religioso representaba para muchas personas un mero formulismo y un recurso de los sacerdotes para sacar dinero a 
los fieles. En el imaginario colectivo «cristianar» era un imperativo ineludible, especialmente ante la eventualidad de una muerte prematura del niño. Téngase en cuenta que todavía en la segunda mitad del siglo XIX en la campaña uruguaya era muy popular el «velorio del angelito», práctica que implicaba la realización de una fiesta en la casa de la familia donde hubiera muerto un niño. Se consideraba que éste había sido librado por Dios de los sufrimientos de este mundo y la familia tendría un intercesor de primer orden ante el Todopoderoso.

\section{Cuadro II}

Bautismos

\begin{tabular}{|l|c|c|c|c|}
\hline Parroquia & $\mathbf{1 8 7 0 - 8 5}$ & Promedio & $\mathbf{1 8 8 6 - 1 9 0 0}$ & Promedio \\
\hline Matriz & 30.351 & 1.896 & 24.285 & 1.619 \\
\hline Aguada & 8.512 & 532 & 14.523 & 968 \\
\hline Unión & 6.053 & 288 & 7.764 & 517 \\
\hline Canelones & 7.249 & 455 & 6.670 & 444 \\
\hline Tala & 6.547 & 409 & 6.512 & 434 \\
\hline Florida & 8.346 & 521 & 9.765 & 651 \\
\hline
\end{tabular}

Fuente: Estadísticas de Bautismos (1870-1900). ACEM, C. 173, c. Estadística. Nacimientos. Bautismos. Defunciones.

La vigencia del bautismo en el secularizado Uruguay es un hecho importante y tiene profundas connotaciones religiosas. Una clave para comprender la eficacia del mismo la brinda el simbolismo del agua, elemento fundamental en el ritual. Las hierofanías acuáticas son muy antiguas y están relacionadas con las cosmogonías y con lo ritual. La inmersión del catecúmeno se considera un acto rebosante de sacralidad y eficacia simbólica pues implica una regeneración, un nuevo nacimiento como hijo de Dios y miembro de su familia: la Iglesia.

Las cifras de la Parroquia San Eugenio, cuadro III, revelan un notorio aumento del número de niños provenientes de parejas unidas civilmente. De un promedio anual de 0.18 para el lapso $1870-1885$, se pasó a uno de 59 entre 1886 y 1900.

En el lejano Departamento de Artigas la «descatolización» se intensificó a partir de la ley de Matrimonio Civil Obligatorio. La débil inserción clerical posibilitó el desarrollo de un cristianismo nominal y tradicional. El discurso oficial no logró permear una religiosidad popular bastante autónoma gestada al influjo de creencias de tipo supersticioso. Los actores de esta religiosidad experimentaban una relación directa y simple con lo numinoso y no tenían 
una conciencia de pecado tal como la predicaban los clérigos. El rápido progreso del matrimonio civil en campaña preocupó profundamente a los obispos..$^{24}$

Cuadro III

Parroquia San Eugenio (Artigas)

\begin{tabular}{|l|c|c|c|c|}
\hline Hijos & $\mathbf{1 8 7 9 - 8 5}$ & Promedio & $\mathbf{1 8 8 6 - 9 0 0}$ & Promedio \\
\hline Legítimos & 4.843 & 302 & 4.578 & 305 \\
\hline Naturales & 3.169 & 198 & 3.134 & 208 \\
\hline $\begin{array}{l}\text { De padres unidos solo } \\
\text { civilmente }\end{array}$ & 3 & 0,18 & 890 & 59 \\
\hline Totales & 8.015 & 500,18 & 8.602 & 572 \\
\hline
\end{tabular}

Fuente: Estadísticas de bautismos y matrimonios efectuados en la Parroquia de San Eugenio del Cuareim (Dpo. de Artigas, (1870-1900). ACEM, C. 173, c. Estadística. Nacimientos. Bautismos. Defunciones.

La autopercepción eclesial y episcopal de los avances secularistas adquirió un tono apocalíptico que revela la profunda crisis que estaba experimentando la mentalidad de cristiandad.

En 1888 Mons. Yéregui expresaba en un documento dirigido al Papa: «Desgraciadamente el desenvolvimiento de los principios liberales, ateos, racionalistas, positivistas y masónicos (...) se han encaramado en el poder y desde allí hacen encarnizada guerra a la religión católica». ${ }^{25}$ Evaluaba la ofensiva anticlerical como un plan de destrucción moral.

Mons. Soler también explicitó su apreciación del proceso en un opúsculo de carácter reservado (1905): « iEs tan triste la situación presente! (...) Es verdad; cada día la impiedad penetra más profundamente en la juventud y en las masa

\footnotetext{
${ }^{24}$ Resulta interesante, para completar el panorama, considerar algunos datos de la la Parroquia de San Pedro en el Departamento de Durazno. Entre los años 1899 y 1903 se realizaron 4306 bautismos: 2085 hijos legítimos, 1702 naturales, y 519 de uniones civiles (Datos estadísticos remitidos por el P. Joaquín Arrospide a Mons. Mariano Soler, 19 de mayo de 1904. ACEM. C. 173, c. Estadística. Nacimientos, Bautismos. Defunciones). El número de bautizados provenientes de uniones civiles representa un $12 \%$ del total mientras que en el caso de San Eugenio era un 10\%. Como dato importante el Párroco P. Joaquín Arrospide, indica que la Parroquia recibió durante el quinquenio dos misiones, una urbana y otra rural. Por fuentes alternativas sabemos que este sacerdote fue un pastor muy preocupado por sus fieles. Hizo esfuerzos concretos para aumentar la influencia eclesial sobre los habitantes de la campaña. De acuerdo a las estadísticas los resultados no fueron muy buenos; allí, como en otros lugares del interior, la carencia de sacerdotes era notoria y el párroco no podía estar simultáneamente en todas las comarcas de su jurisdicción.
}

${ }^{25}$ Mons. I. Ma. Yéregui, Visita Ad Limina....

Hispania Sacra, LXIII

127, enero-junio 2011, 283-303, ISSN: 0018-215-X 
populares, y la indiferencia religiosa extiende su dominio de una manera pavorosa hasta entre los fieles». ${ }^{26}$

Soler debió enfrentar una coyuntura netamente desfavorable para la Iglesia, con amargura y preocupación:

«Se ha perdido el antiguo respeto a la religión y al sacerdote: y no solo su influencia es cada vez menor, sino que se le cubre con el desprecio y con el más odioso desdén. Es una situación insoportable e inaudita, con perspectivas de acrecentamiento, en vez de disminución. (...) En nuestros días las prácticas religiosas son descuidadas en casi todas partes, y en todas partes nuestras creencias sufren los más violentos asaltos. (...) aquellas masas populares, que antes acudían ávidas de oír la palabra evangélica al pie de la cátedra sagrada, hoy han olvidado el camino de la iglesia. (...) es más grande de lo que pudiera manifestar la preocupación que me atormenta acerca del porvenir de la Iglesia y de la sociedad en nuestra patria (...)».27

El comienzo del siglo XX fue una época de dura lucha por la virulencia del anticlericalismo de José Batlle y Ordóñez, que impulsó medidas lesivas para los intereses de la Iglesia: eliminación de imágenes religiosas en hospitales públicos (1906); ley de divorcio (1907); supresión de enseñanza y prácticas religiosas en escuelas públicas (1909); entre otras.

El golpe de gracia fue la Constitución de 1917. Las autoridades eclesiásticas procuraron, a través de los constituyentes elegidos por la Unión Cívica, mantener en todos sus términos el artículo 5, pero los esfuerzos resultaron infructuosos. La Iglesia logró el reconocimiento de la propiedad de todos los edificios destinados al culto, salvo los que estaban en edificios públicos y, fundamentalmente, se emancipó del Patronato que tanto la había limitado, las diócesis vacantes pudieron ser provistas libremente por la Sede Apostólica.

La secularización uruguaya culminó exitosamente para los intereses de los sectores anticlericales. A partir de entonces Uruguay fue reconocido por su sistema político laico, profundamente liberal y democrático.

\section{LAS RESPUESTAS DE LA IGLESIA}

Para enfrentar el creciente anticlericalismo los obispos de la época (Vera, Yéregui y Soler) recurrieron a distintas estrategias. El rol desempeñado por Jacinto Vera fue muy importante para reorganizar la institución; luego de su participación en el Concilio Vaticano I se estrecharon los vínculos entre la iglesia

${ }^{26}$ M. Soler, Memorandum Confidencial al Venerable Clero Secular y Regular, Montevideo, 1905, 3-10.

27 Idem. 
uruguaya y la Santa Sede. Vamos a revisar sucintamente las iniciativas llevadas adelante. Estas fueron coincidentes, en líneas generales, con las ensayadas en otras repúblicas americanas (Chile, Argentina...), pero en Uruguay no lograron revertir el proceso secularizador.

\section{a. Creación de un clero nacional}

La escasez de personal religioso impidió una acción evangelizadora profunda y perdurable. Mons. Vera intentó crear y consolidar el clero nacional, para ello envió a varios jóvenes con inquietudes vocacionales a seminarios argentinos. Los hermanos Rafael e Inocencio Yéregui 28 estudiaron en Buenos Aires; Mariano Soler, ${ }^{29}$ Ricardo Isasa ${ }^{30}$ y Norberto Betancur en Santa Fe. Isasa, Betancur y Soler culminaron su carrera en Roma. Todos tuvieron posteriormente destacado desempeño. Recién en 1880 estuvieron dadas las condiciones para fundar un Seminario Diocesano; fue confiado a la dirección de la Compañía de Jesús y en 1888 llegó a tener 42 estudiantes.

Para mejorar la acción evangelizadora se promovió la inserción de «corporaciones regulares». En 1863 había solamente 3 comunidades religiosas, en 1888 el número subió a 13, y en 1904 a 27. En torno a 1900 sus efectivos, masculinos y femeninos, eran cientos, mayoritariamente extranjeros y establecidos en toda la República. ${ }^{31}$ Trabajaron en la enseñanza -para competir con la escuela vareliana-, asistencia de enfermos, cuidado de huérfanos, atención del culto, etcétera. Se destacaron particularmente los salesianos y jesuitas. Resultaron un instrumento muy eficaz de propaganda y evangelización. Monseñor Soler opinaba que gracias a ellas

«(...) se levanta la parte espiritual de las parroquias de campaña, porque muchas de ellas cuentan ya con Colegios de Hermanas de la Caridad, que forman jóvenes y madres cristianas, las que, con el tiempo, influyen poderosamente, con la virtud y el buen ejemplo, en la constitución cristiana del hogar y de la sociedad. En el presente decenio se han establecido varias congregaciones religiosas de caridad en esta capital y en diversos pueblos de la Diócesis y se trabaja siempre (...)».32

\footnotetext{
${ }^{28}$ Segundo Obispo de Montevideo.

${ }^{29}$ Tercer Obispo y primer Arzobispo de Montevideo.

${ }^{30}$ Administrador Apostólico de Montevideo.

${ }^{31}$ Cfr. ACEM, C. 173 , c. Censo.

${ }^{32}$ M. SolER, Visita Ad Limina (1896), 15, ACEM, Arzobispado de Montevideo, C. 4.
} 


\section{b. Fundación de medios de prensa}

En la década de 1870 se fundaron órganos de prensa oficiales de la curia con el objetivo de enfrentar los embates de la prensa liberal, difundir la doctrina cristiana e informar a los católicos. Entre 1871 y 1877 salió El Mensajero del Pueblo, semanario dirigido por el P. Rafael Yéregui; posteriormente, de 1886 a 1918, apareció La semana Religiosa.

La causa católica contó, además, con un medio semioficial orientado por laicos: el periódico El Bien Público, fundado en 1878 por el insigne poeta Juan Zorrilla de San Martín, que siguió imprimiéndose buena parte del siglo XX. Publicaba cuestiones doctrinales, noticias de actualidad y artículos polémico-apologéticos. En 1885 tuvo problemas con el gobierno por su actitud crítica de la ley de Matrimonio Civil Obligatorio, fue censurado y debió cambiar temporalmente de nombre, pasó a llamarse El Diario Católico.

\section{c. Fomento de la actividad evangelizadora en el interior del país}

Los prelados se preocuparon particularmente por fomentar la evangelización en el interior del país propiciando la realización de misiones rurales. Pretendían combatir lo que en la época denominaban «apatía»e «indiferentismo» y promover el «progreso moral» y «espiritual» de los fieles. ${ }^{33}$ Los propios obispos recorrieron el campo procurando tener un contacto directo con sus feligreses. Durante los días que duraba la misión (entre cuatro y ocho), los sacerdotes realizaban charlas de contenido doctrinal, celebraban misa y administraban los sacramentos del matrimonio, bautismo y confesión. Buscaban eliminar el «amancebamiento» y otros «vicios morales» como el juego, violencia y holgazanería. Al final de cada misión se erigía una cruz en un sitio elevado con el objetivo de perpetuar entre los comarcanos la memoria del acontecimiento.

Se crearon organizaciones dedicadas exclusivamente a las misiones. La más importante fue el «Centro Apostólico San Francisco Javier», fundado el 17 de agosto 1896 por iniciativa de un grupo de damas católicas de Montevideo y con el respaldo de la Compañía de Jesús. ${ }^{34}$ Su propósito era

${ }^{33}$ En 1872 un sacerdote le decía a Mons. Vera: «Ilmo. Sr. Manifiesto mis dolores que me hace concebir este pueblo recién formado (...) Son muy cumplidos unos con los otros pero con la Iglesia (...) se avergüenzan: las visitas, las murmuraciones y el ocio y mate los entretenimientos con que cumplen exactamente» (Carta del Padre Francisco Leivas a Mons. Jacinto Vera, 29 de octubre de 1872. ACEM. Vicariato Apostólico. Correspondencia de Mons. Vera, C. 305, c. 31).

${ }^{34}$ Los detalles de sus primeras empresas han quedado registrados en un importante documento titulado Obra de civilización o viajes del Centro Apostólico a los diecinueve departamentos de la República Oriental del Uruguay por un Padre de la Compañía de Jesús, Montevideo, 1914. 
«(...) llevar la luz de la instrucción moral y religiosa a los moradores de la campaña, que por vivir lejos de todo centro de población, viven en lamentable ignorancia de su último fin. (...) el conocimiento de Dios (...) es lo que el Centro lleva a los alejados del comercio de las ciudades y pueblos; con este conocimiento, que es el fundamental, lleva el Centro a estos infelices la regeneración moral, el orden en su vida y costumbres, la paz con los hombres y la amistad con Dios». ${ }^{35}$

Entre 1896 y 1908 el Centro realizó una gira completa por los 19 departamentos de la República. Los resultados cuantificados revelan una actividad febril: 211 misiones, 23.986 comuniones, 12.524 confirmaciones, 3.016 bautismos y 318 matrimonios regularizados. ${ }^{36} \mathrm{La}$ falta de continuidad en la realización de misiones y la carencia de sacerdotes impidieron una acción prolongada en el tiempo que calara profundamente en los habitantes de la campaña.

\section{d. Desarrollo del asociacionismo católico}

El asociacionismo católico tuvo una época de expansión, especialmente a partir del obispado de Jacinto Vera. Estas organizaciones laicales (cofradías y hermandades) estaban orientadas por sacerdotes, director», «asesor», o «capellán», y poseían estatutos y autoridades propias. Fueron un medio de evangelización urbana y estaban dedicadas a la realización de actos devocionales, piadosos y/o caritativos. La patrona, la Virgen en cualquiera de sus advocaciones, Cristo, o un santo, debía inspirar virtudes y valores.

Los estatutos reglamentaban minuciosamente los actos religiosos y prescribían un código de conducta para sus miembros. Las siguientes disposiciones tomadas del libro de actas de la Pía Unión de Hijas de María (mayo de 1878, Parroquia de la ciudad de Rosario) resultan ilustrativas:

«La profesión pública que hacen las Hijas de María de ser devotas de Nuestra Señora las obliga naturalmente a dedicarse con más empeño que las demás a la práctica de las obras de piedad. Así no dejarán, al levantarse por la mañana, de dar gracias a Dios consagrando a El los primeros pensamientos; rezarán tres Padre Nuestros y Ave Marías a honra de la Santísima Trinidad, un Credo y una Salve, sin perjuicio de otras devociones suyas que tengan de costumbre. Harán, siempre que les sea posible, un rato de oración mental o lectura de algún libro espiritual; harán firme propósito de no ofender a Dios en el día (...). A la noche antes de recogerse harán examen de conciencia, rezarán tres Padre Nuestros y Ave Marías, otro más por las ánimas del Purgatorio y pedirán por último la bendición a María.

35 Ibidem, 339.

36 Ibidem, 332-333.

Hispania Sacra, LXIII

127, enero-junio 2011, 283-303, ISSN: 0018-215-X 
«En todo tiempo y circunstancia harán diligencia y empeño las congregantas en imitar las virtudes, de que tienen un modelo acabado en la vida de María Santísima y de Santa Rosa, particularmente la humildad, la modestia, la pureza, obediencia, mortificación y amor al trabajo.

«Evitarán con todo cuidado las diversiones peligrosas, la compañía de personas ajenas al espíritu de piedad o imbuidas de máximas contrarias a la religión, o corrompidas por malas costumbres. Se guardarán asimismo de la lectura de libros prohibidos».37

Estas disposiciones estaban pensadas y dedicadas a las mujeres, última «reserva moral» de la Iglesia, que «salvarían» a las familias y a la sociedad uruguaya. La hermandad representaba un bastión contra los embates del secularismo. Las congregantas debían preservarse de todo aquello que pudiera ir contra la doctrina eclesiástica y la moral cristiana. El control clerical correspondía al Director, pero involucraba también a las mismas congregantas quienes debían vigilar y denunciar a quienes transgredieran los reglamentos.

Existen varios documentos oficiales de la Iglesia uruguaya que revelan el rol asignado a estas organizaciones. Los prelados insistían recurrentemente en la eficacia salvífica de la incorporación a estas organizaciones y encomiaban a los clérigos para que promovieran las asociaciones patronales en sus respectivas parroquias. ${ }^{38}$ Para autorizar la erección de una cofradía era necesario solicitar permiso al obispo. ${ }^{39}$ En las asociaciones se intentó formar cuadros de resistencia al anticlericalismo. Contribuían, relativamente, a compensar las carencias de personal eclesiástico «clericalizando» a los laicos en organizaciones rígidas donde la obediencia era fundamental. Son testimonio de una etapa de endurecimiento de la Iglesia; constituyen un ejemplo del repliegue clerical y de la forma temerosa en que se miraba al mundo moderno que acechaba contra la ciudadela de la «civilización cristiana».40

\section{e. Los Congresos Católicos}

Entre 1889 y 1911 se realizaron cuatro Congresos Católicos $(1889,1893$, 1900 y 1911), verdaderos cónclaves de laicos, sacerdotes y religiosos de los que surgían iniciativas para hacer más efectiva la tarea de la Iglesia. En el $4^{\circ}$

\footnotetext{
${ }^{37}$ Libro de Actas de la Pía Unión de Hijas de María, 1878, APNSR.

38 Cfr. ARquidiócesis de Montevideo, Esquema de las constituciones Sinodales, Montevideo, 1925, 185-186.

${ }^{39}$ Cfr. Arquidiócesis de Montevideo, Tercer Sínodo Diocesano, Montevideo, 1951, 98.

${ }^{40}$ Estas organizaciones comenzaron a decaer irremediablemente a partir de la década de 1950. La crisis socioeconómica y la inserción de la Iglesia posterior al Vaticano II las hicieron disfuncionales con la realidad histórico-religiosa.
} 
Congreso, convocado por Mons. Isasa en 1911, se concretaron las instituciones que estaban en germen: la Unión Social (coordinación de obras asistenciales y caritativas surgidas bajo el estímulo de la Rerum Novarum de León XIII), la Unión Económica (coordinación de organizaciones católicas dedicadas al ahorro y préstamo), y la Unión Cívica (partido político que se presentó a las elecciones de constituyentes de 1916). Nacieron varias organizaciones que constituyeron una sólida estructura eclesial que aspiraba a cubrir todas las necesidades del cristiano.

\section{f. El Club Católico}

Para contrarrestar el monopolio ideológico del racionalismo en las élites culturales se fundó el Club Católico el 20 de junio de 1875. Pretendía brindar a la juventud religiosa un ámbito de estudio y formación para luchar contra el anticlericalismo reinante en la Universidad. Mons. Jacinto Vera acogió calurosamente esta iniciativa laical, designó directores a Mariano Soler y Ricardo Isasa. El primero resultó un decidido animador del Club, realizó conferencias y cursos destinados a la edificación y formación de los militantes de «la causa» sobre temas muy variados: teorías darwinistas, racionalismo, protestantismo, etc.

\section{g. Acción en el plano educativo}

La reforma escolar impulsada por José Pedro Varela a partir de 1877 buscó imponer una educación estatal gratuita, laica y obligatoria. A partir de entonces la Iglesia estimuló la fundación de una serie de instituciones relacionadas con la enseñanza que buscaban establecer un contrapeso a los avances del laicismo en la educación:

El «Liceo de Estudios Universitarios» en 1877, iniciativa de Mariano Soler con el fin de que se convirtiera en una universidad católica.

El «Instituto Pedagógico» en 1882, para contrarrestar la acción del laicismo en la escuela primaria; Francisco Bauzá, ilustre historiador y legislador católico, fue elegido Presidente. A su amparo se fundaron varias escuelas en Montevideo y en el interior del país, se elaboraron programas especiales para ellas y Bauzá redactó los textos.

La «Asociación de enseñanza Católica» en 1885.

Surgió una extendida red de colegios administrados, en su gran mayoría, por congregaciones religiosas. 


\section{CONCLUSIÓN}

La implantación de la Iglesia en Uruguay fue tan tardía como la colonización española de su territorio. Se trató de un catolicismo epidérmico y formal. La dependencia eclesiástica de la diócesis de Buenos Aires le quitaba a los clérigos orientales dinamismo, creatividad y capacidad de iniciativa. En la larga duración puede apreciarse claramente que careció de recursos económicos significativos, sacerdotes ilustrados, salvo excepciones, y un centro superior de educación. Estuvo mal preparada para enfrentar los desafíos que se le plantearon a partir de la independencia nacional. El Estado se autoproclamó heredero del Patronato y por tanto, reivindicó su hegemonía sobre la Iglesia.

La Constitución de 1917 fue interpretada por los católicos como una derrota. Adquirieron conciencia de la pérdida definitiva de la vieja y añorada estructura de «cristiandad» y de la irreversible realidad de convivir en una sociedad plural y laica. Esto favoreció el repliegue eclesial y la paulatina merma de su influencia sociocultural. Fenómenos nuevos como el rápido desarrollo de confesiones protestantes, pentecostales y cultos sincréticos de origen afrocristianos, coadyuvaron en el transcurso del siglo XX a disminuir notoriamente la ya cuestionada ascendencia católica. 